\title{
Letters
}

Website: www.bmj.com

Email: letters@bmj.com

\section{Cancer survival in Britain}

\section{Cancer chemotherapy costs money}

EDITOR-I strongly endorse Sikora's claim that poor rates of survival from cancer in the United Kingdom reflect a lack of NHS resources. ${ }^{1}$ Increasing the number of specialist oncologists will not, however, make up for the massive shortfall in funds required to provide these oncologists with the essential tools of their trade.

Recent review of the budgetary allocation to Addenbrooke's Oncology Centre identified that, on average, $£ 1700$ a year is available to spend on drugs for any individual patient with cancer. Since a single course of chemotherapy may cost between $£ 50$ and $£ 1500$, oncologists cannot be expected to deliver the quality of care the public expects to receive. There are no other untapped sources of funding. Our clinical practice is already heavily subsidised: about one in six of all new patients with cancer referred to Addenbrooke's receives his or her standard chemotherapy courtesy of funds raised from industry sponsored research.

The government cannot claim commitment to improving cancer care while patients are being denied effective treatments on the grounds of lack of affordability.

P G de Takats consultant medical oncologist Addenbrooke's Hospital, Cambridge CB2 2QQ ys31@dial.pipex.com

1 Sikora K. Cancer survival in Britain. BMJ 1999;319;461-2. (21 August.)

\section{Diagnosis in primary care is important factor}

EDITOR-Sikora paints a bleak picture of the quality of cancer care in Britain compared with France, Germany, and Sweden. ${ }^{1}$ I agree with most of his editorial but take issue with his dismissal of diagnostic delay in primary care as being an important factor. The fact that patients reach secondary care at similar stagings throughout Europe should not allow complacency. Primary care diagnostic oncology in Britain may simply be as bad as that in the rest of Europe.

The Medical Defence Union has reported that failure and delay in diagnosis consistently account for nearly one third of notified complaints concerning general practitioners. ${ }^{2}$ As the most common clinical condition associated with diagnostic failure or delay is missed malignancy, it is salutary to note that the primary care evidence for the importance of chronic cough as a symptom of lung cancer or haematuria as a symptom of urological malignancy remains

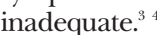

The focus in any attempt to improve survival from cancer must not continue to ignore the primary care perspective. We need to address the importance of ensuring prompt diagnosis and referral in patients presenting to primary care clinicians with possible symptoms of an underlying malignancy; this is a neglected area of research and education.

Nicholas Summerton clinical senior lecturer in primary care medicine (University of Hull) The Surgery, Winterton, Scunthorpe DN15 9TA NSummerton@medschoolhullac.uk

1 Sikora K. Cancer survival in Britain. BMJ 1999;319:461-2. (21 August.)

2 Green S, Price J. Complaints. Pulse 4 April 1998:63, 67. 3 Liedekerken BMJ, Hoogendam A, Buntinx F, van der Weyden, de Vet HCW Prolonged cough and lung cancer: Weyden, de Vet HCW. Prolonged cough and lang cance clinical decision making. Br J Gen Pract 1997; 47:505.

4 Bruntinx F, Wauters $H$. The diagnostic value of macroscopic

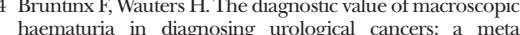
haemalysis. Fam Pract 1997;14:63-8.

5 Summerton N. Diagnosing cancer in primary care. Oxford: 5 Summerton N. Diagnosing
Radcliffe Medical, 1999.

\section{Reliable data on stage distribution are} essential

EDITOR-Sikora's editorial on cancer survival concluded that poorer survival in Britain compared with Europe overall is mainly due to lower quality care. ${ }^{1}$ Delays in diagnosis (and therefore differences in stage) were not considered important: indeed, Sikora stated that the stage distribution was similar in all European countries. The available evidence suggests that this is not the case.

The table gives five year age adjusted relative survival for selected tumours in England and Europe overall for the most recent years covered by EUROCARE ${ }^{2}$ and shows that survival in England was considerably lower than the European average for

Five year age adjusted relative survival in England and Europe overall, for both sexes combined

\begin{tabular}{lccr} 
Tumour site & $\begin{array}{c}\text { England } \\
(\mathbf{\%})\end{array}$ & $\begin{array}{c}\text { Europe } \\
\text { overall (\%) }\end{array}$ & $\begin{array}{c}\text { Difference } \\
\mathbf{( \% )}\end{array}$ \\
\hline Stomach & 11.9 & 21.0 & -9.1 \\
\hline Colon-rectum & 42.0 & 46.9 & -4.9 \\
\hline Breast (women) & 67.6 & 73.4 & -5.8 \\
\hline Prostate & 43.1 & 58.3 & -15.2 \\
\hline Kidney & 38.2 & 47.5 & -9.3 \\
\hline $\begin{array}{l}\text { Testis } \\
\begin{array}{l}\text { Non-Hodgkin's } \\
\text { lymphoma }\end{array}\end{array}$ & 95.0 & 93.1 & 1.9 \\
\hline \begin{tabular}{l} 
Hodgkin's disease \\
\hline
\end{tabular} & 75.2 & 48.6 & -3.4 \\
\hline
\end{tabular}

tumours treated mainly by surgery (tumours of the stomach, colorectum, kidney, and breast). By contrast, for tumours treated mainly by chemotherapy or combined approaches, the prognosis in England was close to the European average. Thus survival for testicular cancer and Hodgkin's disease was the same in England and Europe overall and survival for non-Hodgkin's lymphoma was close to the European mean. Since stage at diagnosis is more important for tumours treated by surgery than for tumours treated with chemotherapy, these data suggest that advanced stage at diagnosis is a major reason for low cancer survival in England.

In general, the outcome of cancer depends on both stage at diagnosis and efficacy of treatment. To distinguish these, and to analyse their effect on differences in survival between countries, it is necessary to have reliable data on stage distribution. Stage depends on the thoroughness of diagnostic work up, which is likely to vary by country: in areas using sophisticated techniques to detect occult metastases a "localised" diagnosis is more likely to be that than one made in an area where these techniques are not available. ${ }^{3}$ To have a reliable picture of stage distribution, therefore, it is necessary to know what staging examinations were performed, and this is the next step in the EUROCARE survival analysis programme.

\section{Advice to authors}

We prefer to receive all responses electronically, sent either directly to our website or to the editorial office as email or on a disk. Processing your letter will be delayed unless it arrives in an electronic form.

We are now posting all direct submissions to our website within 24 hours of receipt and our intention is to post all other electronic submissions there as well. All responses will be eligible for publication in the paper journal.

Responses should be under 400 words and relate to articles published in the preceding month. They should include $\leqslant 5$ references, in the Vancouver style, including one to the BMJ article to which they relate. We welcome illustrations.

Please supply each author's current appointment and full address, and a phone or fax number or email address for the corresponding author. We ask authors to declare any competing interest. Please send a stamped addressed envelope if you would like to know whether your letter has been accepted or rejected.

Letters will be edited and may be shortened.

www.bmj.com

letters@bmj.com 
Analyses of the existing EUROCARE database show that differences in survival from breast cancer between countries were established within the first six months after diagnosis. The excess risk of death within this period was higher for the United Kingdom than for European patients overall; after this period the difference in excess risk of death narrowed. ${ }^{4}$ Patients with breast cancer who die within six months of diagnosis probably have advanced stage disease. This again suggests that advanced stage at diagnosis is a major determinant of low survival from breast cancer in the United Kingdom, and a similar pattern occurred with colorectal cancer.

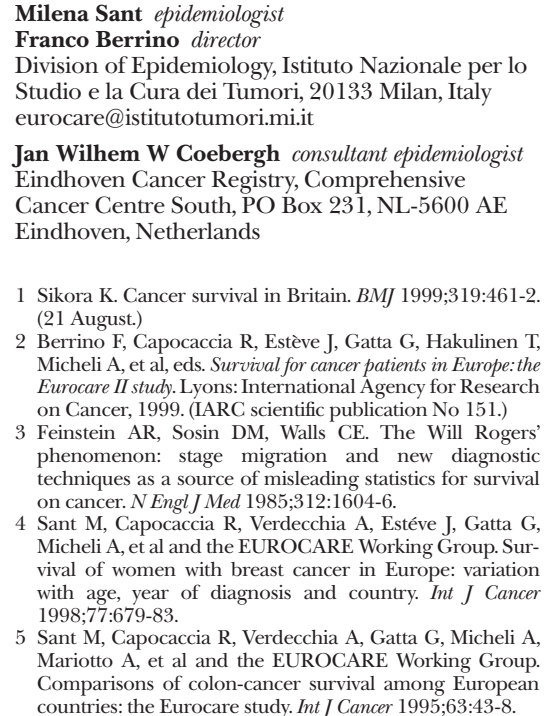

Jan Wilhem W Coebergh consultant epidemiologist Eindhoven Cancer Registry, Comprehensive Cancer Centre South, PO Box 231, NL-5600 AE Eindhoven, Netherlands

1 Sikora K. Cancer survival in Britain. BMJ 1999;319:461-2. (21 August.)

2 Berrino F, Capocaccia R, Estève J, Gatta G, Hakulinen T, Micheli A, et al, eds. Survival for cancer patients in Europe: the Eurocare II study. Lyons: International Agency for Research on Cancer, 1999. (IARC scientific publication No 151.)

3 Feinstein AR, Sosin DM, Walls CE. The Will Rogers' Feinstein AR, Sosin DM, Walls CE. The Will Rogers' phenomenon: stage migration and new diagnostic techniques as a source of misleading statistics for survival on cancer. N Engl J Med 1985;312:1604-6.

4 Sant M, Capocaccia R, Verdecchia A, Estéve J, Gatta G, Micheli A, et al and the EUROCARE Working Group. Survival of women with breast cancer in Europe: variation with age, year of diagnosis and country. Int J Cancer 1998;77:679-83.

5 Sant M, Capocaccia R, Verdecchia A, Gatta G, Micheli A Mariotto A, et al and the EUROCARE Working Group Comparisons of colon-cancer survival among European countries: the Eurocare study. Int J Cancer 1995;63:43-8.

\section{Perhaps Britain should adopt French} model

EDITOR-In his editorial on survival from cancer in Britain, ${ }^{1}$ Sikora explores possible reasons for the poorer outcomes compared with those in other European countries such as France, which enjoy comparable prosperity. ${ }^{2}$ The differences in survival from treatment of common cancers of the lung, bowel, breast, and prostate are likely to be multifactorial, including tumour site specific multidisciplinary assessment for all new patients, quality of surgery, histopathology, imaging, radiotherapy, and selection of adjuvant chemotherapy. Systematic defects in the quality of any of these elements are likely to compromise outcome.

The framework for achieving the necessary uniform quality of cancer services suggested by the Expert Advisory Group on Cancer was the establishment of cancer units and centres based largely on existing district general and teaching hospitals respectively. ${ }^{3}$ Much of the existing evidence suggests, however, that patients with common cancers such as breast cancer have better outcomes in specialist centres. ${ }^{4}$

France has, as part of its state funded cancer services, a small number of centrally and separately funded major cancer centres providing cancer site specialised treatment and research facilities in Paris and in a limited number of cities in the regions. This has enabled protocol driven multidisciplinary cancer management, skilled staff, modern equipment, and research and development facilities to be concentrated in a limited number of institutions. In the 1970s the idea of establishing a limited number of major cancer centres along similar lines to the French centres was mooted in the United Kingdom but never came to fruition.

A formal evaluation of cancer outcomes since the introduction of the Calman-Hine model is now needed. ${ }^{5}$ If this shows no great improvement we should look seriously at adopting the French model to deliver the improvement in cancer survival rates that patients in the United Kingdom deserve.

Ian Kunkler consultant in clinical oncology Western General Hospital, Lothian University Hospitals NHS Trust, Edinburgh EH4 2XU jmd@wght.demon.co.uk

1 Sikora K. Cancer survival in Britain. BMJ 1999;319:461-2. (21 August.)

2 Coebergh J, Sant M, Berrino F, Verdecchia A. Survival of adult cancer patients in Europe diagnosed from 19781989: the Eurocare 11 study. Eur J Cancer 1998;34:2137-8. 3 Expert Advisory Group on Cancer. A policy framework for 3 Expert Advisory Group on Cancer. A policy framework for Commissioning

4 Kingsmore DB, Hole D, Gillis C, George WD. Conservation surgery and specialist treatment. Eur J Cancer 1998; 34(suppl 5):S46.

5 Calman KC, Hine D. Expert Advisory Group on Cancer Services. A policy framework for commissioning cancer services. a report to the chief medical officers of England and Wales. London: Department of Health and the Welsh Office, 1995.

\section{Survival for over five years after} diagnosis does not mean cure

EDITOR-Sikora's editorial on cancer survival in Britain is disturbing, and few British oncologists would disagree with his list of possible reasons why that survival is poorer than that of people in comparable European countries. ${ }^{1}$ Whether data from between one and two decades ago remain valid is yet to be seen.

Sikora is wrong, however, in stating that "most patients can be considered cured after [surviving five years from diagnosis]." This is certainly not true for breast cancer, the commonest cancer in women in the European Union: survival curves in women given no adjuvant chemotherapy have been shown not to parallel those of women of the same age without breast cancer until beyond 25 years from diagnosis. ${ }^{2}$

What is important is not just duration of survival but cure. Survival can be eked out with cytotoxic systemic treatments after metastatic relapse in some cancers that will inevitably prove fatal. What cancer registries are generally unable to do is present data on survival after relapse, which may be influenced by factors related to the patient, clinician, and treatment. In comparing quality of care we are left with a rather crude measure: overall survival over what is an inadequate period for some common cancers

Alan Rodger professor of radiation oncology Karen Taylor fellow in radiation oncology William Buckland Radiotherapy Centre, The Alfred, Melbourne, Australia
1 Sikora K. Cancer survival in Britain. BMJ 1999;319:461-2. (21 August.)

2 Kerr GP, Kunkler IH, Langlands AO, Rodger A. (In)curability of breast cancer: a 30-year report of a series of 3933 patients. Breast 1998;7:190-4.

\section{Article on bayesian methods was right}

EDITOR-Bayes's theorem was invoked in a paper about screening for HIV by Meyer and Pauker in 1987. ${ }^{1}$ The philosophy imparted had much to do with attitudes to screening for HIV infection and its legacy on the present world pandemic.

These authors assumed a false positive rate of $0.005 \%$ for combined Western blot testing and enzyme linked immunosorbent assay (ELISA) and a seroprevalence rate in the general population of $0.01 \%$ (this represented the incidence of HIV infection in female blood donors in the United States in 1986). Thus testing a population of 100000 people would detect 10 genuine cases of HIV infection and yield five false positive results. These odds were considered to be an argument against screening. The fact that female blood donors were not truly representative of the general population and that random false positivity in testing could be appreciably reduced by repeat testing went unnoticed.

This would seem to underscore a statement at the end of Spiegelhalter et al's article: "The perceived problems with the bayesian approach largely concern the source of the prior and the interpretations of the conclusions."

James E Parker retired paediatrician

289 McCallum Road, Abbotsford, British Columbia, Canada V2S 8A1

james@ve7drp.ampr.org 1 Meyer KB, Pauker SG. Screening for HIV: can we afford
the false positive rate? N Engl J Med 1987;317:238-4.
2 Spiegelhalter DJ, Myles JP, Jones DR, Abrams KR. Methods
in health service research: an introduction to bayesian
methods in health technology assessment. BMJ 1999;319: 508-12. (21 August)

\section{Evidence based palliative care}

\section{General palliative care should be evaluated}

Editor-Higginson rightly calls for the development of standards for all services that provide palliative care and for the evaluation of aspects of palliative care that are so far unevaluated. ${ }^{1}$ Levels of need for palliative care are likely to continue rising, with the increasing incidence of cancer as the population ages and with improved survival from cancer. It is important that we plan to meet the increased need with cost effective measures. In addition to the areas for further attention that Higginson mentions, we would add the whole area of general palliative care, an issue only alluded to in the editorial.

Palliative care should be at the core of the work of every health professional. The term "general palliative care" refers to the provision of palliative care by health profes- 
sionals, in the community or in hospitals, who are not specialists in palliative care. General practitioners, district nurses, and other members of the primary care team are recognised to be central to its provision.? They also have an important role in coordination and the maintenance of continuity, which should not be weakened, ${ }^{3}$ as people spend most of the last year of life at home. ${ }^{4}$ Most people with terminal cancer would prefer to die at home if possible. ${ }^{5}$

Generalists in hospital also have a major role. In Scotland 52\% of deaths from cancer of the large bowel, lung, and breast (1986-95) occurred in an acute hospital. In Fife $12.8 \%$ of hospital bed days in 1997-8 were for the care of people with cancer.

Specialist palliative care services undoubtedly provide essential support, advice, and skill to generalists as well as providing the bulk of care for some patients. To meet rising levels of need for palliative care effectively, however, we should nurture and harness the contribution of generalists, who make a substantial contribution to meeting these needs. This requires the development of local standards for general palliative care and research into effective ways of improving such care. The introduction of better monitoring and audit of general palliative care is also important.

We should not leave generalists behind as we work to meet rising need for palliative care in the coming years; to do so is unlikely to be sustainable or in the interests of patients and their families.

Gordon McLaren senior registrar in public health medicine

Fife Health Board, Cupar, Fife KY15 5UP gmclaren@fhblib.demon.co.uk

Clive Preston consultant in palliative medicine Fife Palliative Care Service, Kirkcaldy, Fife KY1 2LF Bob Grant Macmillan general practitioner facilitator Fife Cancer Services, Victoria Hospital, Kirkcaldy, Fife KY2 5AH

Higginson IJ. Evidence based palliative care. BMJ 1999 319:462-3. (21 August.)

2 Doyle D. The way forward-policy and practice. In: National Council for Hospice and Specialist Palliative Care Services. Report of a joint conference:promoting partnership:planning and managing community palliative care. London: NAHAT and NCHSPCS, 1998:44-50. (Occasional paper 15.)

3 O'Neill B, Rodway A. ABC of Palliative Care: Care in the community. BMJ 1998;316:373-7.

4 Seale C, Cartright A. The year before death. Aldershot: Avebury, 1994.

5 Townsend J, Frank AO, Fermont D, Dyer S, Karran O, Walgrave A. Terminal cancer care and patients' preference for place of death: a prospective study. BMJ 1990;301:415-7.

Specialist palliative care teams are going to have to take on end stage non-cancer diseases

EDITOR-For too long we in the hospice world have basked in the uncritical adulation of the public and the admiration of colleagues in hard pressed hospitals and general practices, both in Britain and in many other countries throughout the world. But if specialist palliative care is so good then producing evidence of both its quality and its cost effectiveness should be possible. Anecdotal reports just will not do; the difficulties of objective measurements described by Higginson in her editorial do not mean that better designed studies cannot be set up.
This is particularly important if specialist palliative care teams are now to take on the care of patients with end stage non-cancer diseases. Prospective studies will be essential so that we have some evidence based data on the outcome of interventions in these patients. There is no doubt that pressure to take on this role exists and will increase, whether from colleagues, bed managers, or members of the general public. As one man said to me recently, "What your team has been able to do for my brother with his lung cancer has been wonderful, tremendous. My family and I cannot thank you enough," and then with great bitterness he added, "Why could you not have done the same for my wife when she had a stroke?"

Tim Lovel consultant physician in palliative medicine St Benedict's Hospice, Monkwearmouth Hospital, Sunderland SR5 1NB

tim.lovel@phw-tr.northy.nhs.uk

1 Higginson IJ. Evidence based palliative care. BMJ 1999; 319:462-3. (21 August)

\section{Spurious asystole with use of manual defibrillators}

\section{Users should not rely on monitoring through paddles, using any type of gel pad, once shocks have been delivered}

EDITOR-Many readers will be aware that in 1998 a problem was identified in the United Kingdom that is highly relevant to some users of manual defibrillators. The original report (which led to a safety notice from the UK Medical Devices Agency ${ }^{1}$ ) related to the use of the Hewlett Packard Codemaster defibrillator in conjunction with gel pads. After one or more defibrillatory shocks an electrical "offset" could influence the monitor on the defibrillator to show a straight line (either continuous or broken), even when ventricular fibrillation was still present or had recurred. This spurious asystole could last long enough to delay further shocks and could thereby hinder the prospects of a successful resuscitation. As far as I am aware, no definitive studies have yet been published to determine how widespread the problem might be, and how far other equipment may also be implicated.

At the Royal Sussex County Hospital we have recently identified an exactly similar problem with a defibrillator from a different manufacturer used in conjunction with gel pads. Further investigation showed that periods of spurious asystole may last for, at worst, three or four minutes.

Rescuers relying on monitoring through defibrillating paddles during an emergency may have no reason to suspect that they are being misled unless conventional electrocardiographic monitoring is conducted simultaneously through independent electrodes. The phenomenon may therefore have escaped attention on numerous occasions. It is nevertheless of considerable clinical importance.

Until the extent of the problem has been fully identified, we recommend that users of manual defibrillators should not rely on monitoring through paddles, using any type of gel pad, once shocks have been delivered. It seems wise to establish independent monitoring as quickly as possible. I believe that all conventional monitoring electrodes that are currently available are of the silver/ silver chloride type that should not be subject to polarisation for more than a very brief period.

I hope that readers may take any opportunity of identifying instances when spurious asystole is shown on defibrillator monitors so that they can inform manufacturers and regulatory bodies. Formal studies would have the advantage of quantifying the risk, bearing in mind that some equipment or combinations of equipment may give reliable information.

I understand that $3 \mathrm{M}$, the leading manufacturer of gel pads, has included advice in its packs that they should not be used for monitoring purposes. Unfortunately, many users may not yet have seen the warning because the packs have a commendably long shelf life, and older stock will still be in widespread use. $3 \mathrm{M}$ has pointed out that gel pads were not designed for, nor intended as, a coupling medium for reading electrocardiograms, but this fact is not widely known.

I know of no instances of the problem occurring with stick-on pads of the type used with automated defibrillators.

Douglas Chamberlain honorary professor, University of Wales College of Medicine

Hove, East Sussex BN3 6DH

chambda@pavilion.co.uk

1 Medical Devices Agency. Hewlett Packard Codemaster XL, $\mathrm{XL}+, 100$ defibrillators. Problem: possible loss of ECG momitoring via paddles following defibrillation using gel pads. London: MDA, 1998. (SN 9819, May 1998.)

\section{Manufacturer's comment}

Editor-We welcome Professor Chamberlain's action in bringing this information to the notice of people likely to use a defibrillator and are grateful for the opportunity to add the following comments.

The potential for excessive time delay between the administration of a shock and display of an electrocardiographic trace is not unique to $3 \mathrm{M}$ defibrillation pads. Any defibrillation gel $\mathrm{pad} /$ paddle combination or defibrillation paste/paddle combination in which the offset potential after a shock exceeds the input saturation limit of the defibrillation system will result in an excessive time delay between the administration of that shock and the display of an electrocardiogram.

After receiving a few reports of customers using the product for monitoring electrocardiograms $3 \mathrm{M}$ added a warning to the 3M Defib-Pad packaging at the beginning of this year to clarify how not to use the product. Because patient safety is of utmost importance to $3 \mathrm{M}$, a clear warning was included as follows:

"Do not monitor heart rhythm through a defibrillator paddle/3M Defib-Pad combination because there may be an excessive time delay between the administration of a shock and an ECG trace display." 
The 3M Defib-Pad has never been intended for monitoring electrocardiograms. The product is clearly described as a conductive gel pad for defibrillation and cardioversion, and the instructions for use clearly set out how to use the pads for these procedures. $3 \mathrm{M}$ believes that there is no safety issue regarding the use of the $3 \mathrm{M}$ Defib-Pad when used for its intended purpose - that is, as a conductive pad for defibrillation and cardioversion.

Users should refer to instructions for use provided by the manufacturers of the defibrillation pads or paste and the defibrillators in all cases and should consult the manufacturers of these products for their advice on their suitability for trace monitoring.

To ensure that you have a display of a trace after a shock, use silver/silver chloride electrocardiographic monitoring electrodes.

If you have any questions or comments about this matter please contact Derek J Wright, technical service specialist (dwright@ mmm.com; tel: 01509613151 in the United Kingdom or + 441509613151 from outside the United Kingdom).

Kenneth W Bartelt technical director 3M Medical-Surgical Division, 3M Health Care, 3M Center, St Paul, MN 55144-1000, USA

\section{Relation of $C$ pneumoniae antibodies to ischaemic heart disease}

\section{Why were samples weakly positive for IgG antibodies not tested for IgA antibodies?}

EDITOR-The relation of Chlamydia pneumoniae antibodies to ischaemic heart disease reported by Strachan et al, and the commentary on the paper, deserve comment. ${ }^{1}$ An association is reported between IgA antibody at the start of the study and prevalent ischaemic heart disease or subsequent death due to ischaemic heart disease. Presumably, serum samples with an IgG antibody titre of $<1$ in 16 were not tested for IgA antibody because it was thought that IgA antibody would not exist. Why, however, were 310 samples that were weakly positive for IgG antibodies not tested for IgA antibodies? Surely some of these could have been weakly positive for IgA antibodies at 1 in 16 and so have influenced the interpretation of results?

Persistent IgA antibody is thought to indicate a chronic infection, as is persistent IgG antibody. Conceptually, therefore, it is difficult to understand why significance should apply apparently only to the presence of IgA antibodies, particularly as others have shown an association with IgG antibodies. Furthermore, as West mentions, there is a problem of relating events to antibody measured only once. ${ }^{1}$ Obviously, IgA antibodies may persist but also disappear. We wonder what proportion of the 1411 men without IgA antibody had it well before or just before serum collection or, indeed, in the years afterwards? It is difficult to accept the association between antibody and disease at face value.

Whether or not IgA antibody is associated with prevalent or fatal incident ischaemic heart disease, only about $8 \%$ of men with such disease had a moderate titre. This figure seems remarkably small compared with the large proportion reported by Boman et al. ${ }^{2}$ Nevertheless, Strachan et al suggest that IgA antibody may be a better marker of persistent inflammation than $C$ pneumoniae organisms in the arterial wall, the immune response increasing the risk of plaque rupture. While $C$ pneumoniae may localise preferentially in cardiovascular tissue, it has been found at other sites (spleen, liver), in veins, ${ }^{3}$ and, contrary to the statement of West, in peripheral blood monocytes. These positive monocytes, in addition to those in atheromatous tissue, may also contribute to antibody production. About half of middle aged blood donors (many of whom must have atherosclerosis) and about three fifths of subjects with cardiovascular disease have such positive monocytes. ${ }^{2}$

$C$ pneumoniae exists not only in atheromatous coronary vessels but in atheromatous lesions of all major arteries. ${ }^{3}$ These organisms must contribute to total antibody production. The relation, if any, between antibody and disease specific to coronary vessels becomes increasingly difficult to comprehend.

David Taylor-Robinson emeritus professor of genitourinary microbiology and medicine Brenda J Thomas research fellow Department of Genitourinary Medicine and Communicable Diseases, Imperial College School of Medicine, St Mary's Hospital, London W2 1NY

1 Strachan DP, Carrington D, Mendall MA, Ballam L, Morri J, Butland BK, et al. Relation of Chlamydia pneumonia serology to mortality and incidence of ischaemic heart disease over 13 years in the Caerphilly prospective heart disease study. [With commentary by $\mathrm{R} R$ West.] $B M$ / 1999;318:1035-9. (17 April.)

2 Boman J, Soderberg S, Forsberg J, Birgander LS, Allard A Persson K, et al. High prevalence of Chlamydi pneumoniae DNA in peripheral blood mononuclear cells in patients with cardiovascular disease and in middle-aged blood donors. J Infect Dis 1998;178:274-7.

3 Taylor-Robinson D, Thomas BJ. Chlamydia pneumoni Taylor-Robinson D, Thomas BJ. Chlamydia pneumonia in arteries, the facts, their interpr

Finnish study finds significant association between raised IgG, but not IgA, titres and mortality

EDITOR-Strachan et al show an association between IgA antibodies to Chlamydia pmeumoniae suggestive of chronic infection and subsequent risk of death from ischaemic heart disease which seems to be largely independent of conventional cardiovascular risk factors. ${ }^{1}$ Atherosclerosis is an inflammatory disease with a possible infectious aetiology, but the importance of raised $C$ pneumoniae antibody titres over time and the need for treatment are not known.

We investigated prospectively the importance of raised $C$ pneumoniae antibody titres as an independent factor for mortality over a mean follow up of 6.5 years in an elderly population. During 1990-1 we recruited 1196 people, nearly the whole population of those aged $\geqslant 64$ in a community in southwestern Finland (488 men, mean age 72, range 64-97; 708 women, mean age 74, range 64-96). Most (90\%) of the participants lived at home; $15 \%$ of the men and $3 \%$ of the women were current smokers, while $55 \%$ and $6 \%$ respectively were ex-smokers. ${ }^{2}$ Serum samples for measuring IgG and IgA antibodies to $C$ pneumoniae by microimmunofluorescence were obtained on enrollment. Titres were categorised as none or low ( $\operatorname{IgG} \leqslant 16, \operatorname{IgA} \leqslant 8$ ), intermediate (IgG 32-256, IgA 16-64), or high (IgG $\geqslant 512$, IgA $\geqslant 128)$. Antibodies were considered to be raised in the intermediate and high categories. All deaths up to the end of 1997 were recorded by Statistics Finland and classed according to the ninth revision of the international classification of diseases (ICD-9).

Altogether 200 deaths had complete data (109 among men); coronary heart disease (ICD-9 codes 410-414) accounted for 67 deaths (42 among men), and cerebrovascular diseases (ICD-9 codes 430438 ) for 28 (10 among men). The associations between raised $\operatorname{IgG}$ and IgA antibodies and mortality adjusted for the potential confounding factors analysed as forced variables (table) were assessed using the Cox proportional hazards regression model.

Raised IgG titres were a significant independent risk factor for mortality from cerebrovascular disease among men (hazard ratio 4.93 (95\% confidence interval 1.4 to 17.3); $\mathrm{P}=0.0092$ ) (table), but not among women. No significant relations between raised titres and mortality from coronary heart disease or all causes were found among men or women. Contrary to the finding of Strachan et $a{ }^{1}{ }^{1}$ we found no significant association between raised IgA titres and mortality from any of these causes.

Infections trigger the rupture of atheromatous plaques and induce thrombotic events, thus favouring the development of artery occlusions. ${ }^{3}$ The presence of $C$ pneumoniae in arterial lesions seen in necropsy specimens using the polymerase chain reaction or immunocytochemistry is related to raised IgG antibody titres to $C$ pneumoniae in serum obtained a mean of 8.8 years before death. ${ }^{4}$ Similarly, we found that raised IgG antibody titres predicted significantly increased

Relative hazard ratios (95\% confidence intervals) for raised IgG antibody titres to Chlamydia pneumoniae in predicting deaths from cerebrovascular disease among men

\begin{tabular}{ll} 
& Hazard ratio $(\mathbf{9 5} \% \mathbf{~ C l})$ \\
\hline Raised IgG titres & $4.93(1.4$ to 17.3$)$ \\
\hline Forced variables: & \\
\hline Age & $1.14(1.0$ to 1.2$)$ \\
\hline Smoking & $1.02(0.4$ to 2.7$)$ \\
\hline Blood pressure & $1.02(0.9$ to 1.0$)$ \\
\hline Body mass index & $0.79(0.6$ to 0.9$)$ \\
\hline FEV & $0.99(0.9$ to 1.0$)$ \\
\hline Social status & $0.77(0.3$ to 1.7$)$ \\
\hline Diabetes mellitus & $5.11(0.7$ to 34.1$)$ \\
\hline
\end{tabular}

$\mathrm{FEV}_{1}=$ forced expiratory volume in one second. 
mortality from cerebrovascular disease in elderly men over a mean follow up of 6.5 years independently of other potential risk factors. Our data provide further support for the view that the use of antimicrobial drugs in suspected chronic or recurrent $C$ pneumoniae infections should be considered, particularly in patients at high risk, such as those with increased thickness of the carotid artery wall. ${ }^{5}$

Leena von Hertzen senior researcher

Finnish Lung Health Association, Sibeliuksenkatu

11 A 1,00250 Helsinki, Finland

lvhertzen@filha.fi

Raimo Isoaho senior lecturer in general practice Department of Public Health and General Practice, University of Turku, Lemminkäisenkatu 1,20520 Turku, Finland

Sirkka-Liisa Kivelä professor of general practice Unit of General Practice, Oulu University Hospital, Aapistie 1, 90220 Oulu, Finland

Pekka Saikku research professor

National Public Health Institute, PO Box 310, 90101 Oulu

1 Strachan DP, Carrington D, Mendall MA, Ballam L, Morris $\mathrm{J}$, Butland BK, et al. Relation of Chlamydia pneumoniae serology to mortality and incidence of ischaemic heart disdisease study. [With commentary by $\mathrm{R} R$ West.] $B M$ J 1999;318:1035-9. (17 April)

2 Isoaho $\mathrm{R}$, Puolijoki H, Huhti E, Kivelä S-L, Tala E Prevalence of asthma in elderly Finns. J Clin Epidemio 1994;47:1109-18.

3 Kuo C-C, Campbell LA. Is infection with Chlamydia pneumoniae a causative agent in atherosclerosis? Mol Med Today 1998;4:426-30.

4 Davidson M, Kuo CC, Middaugh JP, Campbell LA, Wang SP, Newman WP, et al. Confirmed previous infection with Chlamydia pneumoniae (TWAR) and its presence in early coronary atherosclerosis. Circulation 1998;98:628-33.

5 O'Leary DH, Polak JF, Kromnal RA, Manolio TA, Burke O'Leary DH, Polak JF, Kromnal RA, Manolio TA, Burke
GL, Wolfson SK Jr, et al. Carotid-artery intima and media GL, Wolfson SK Jr, et al. Carotid-artery intima and media
thickness as a risk factor for myocardial infarction and stroke in older adults. N Engl J Med 1999;340:14-22.

\section{Breast feeding and obesity}

\section{Relation may be accounted for by social factors}

EDITOR-In their paper on breast feeding and obesity von Kries et al report that, in a large sample of children $(n=13345)$ who ease over 13 years in the Caerphilly prospective hear

were aged 6 in 1997, the lowest prevalence of overweight and obesity at that age was in those who had been breast fed for longest. By contrast, analysing data from our national longitudinal study of children born in $1946(\mathrm{n}=3731)^{2}$ in a comparable way, we found no significant relation of breast feeding with overweight or obesity at age 6 and a suggestion that the lowest prevalence of overweight and obesity at that age was associated with the shortest period of breast feeding (table)

These findings lead us to question von Kries et al's conclusion that childhood overweight and obesity are associated with the composition of breast milk, as does our biologically implausible finding that the greatest risk of overweight or obesity was in those children who were breast fed for longest and those who were never breast fed (table).

It seems likely that the difference in findings between our study and that of von Kries et al, and their finding of a relation between breast feeding and overweight and obesity, may both be accounted for by social factors associated with breast feeding. In Britain the prevalence of breast feeding has changed greatly over the past 60 years and has changed within classes. ${ }^{3-5}$ Breast feeding today is more likely to be a matter of choice, which itself would be distributed unevenly across such social factors as class and maternal occupation.

Michael Wadsworth director m.wadsworth@ucl.ac.uk

Sarah Marshall research assistan

Rebecca Hardy scientific staff

MRC National Survey of Health and Development, University College London Medical School, Department of Epidemiology and Public Health, London WC1E 6BT

Alison Paul scientific staff

MRC Human Nutrition Research Resource Centre, Cambridge CB4 1XJ

Duration of breast feeding and prevalence of being overweight* or obese† among 6 year olds living in United Kingdom in 1952, with adjusted odds ratios for independent risk factors associated with being overweight or obese in logistic model for 3550 children aged 6 in United Kingdom in 1952

\begin{tabular}{|c|c|c|c|c|}
\hline & \multicolumn{2}{|c|}{ Prevalence $(\%)(95 \% \mathrm{CI})$ for: } & \multicolumn{2}{|c|}{ Odds ratio $(90 \% \mathrm{Cl})$ for: } \\
\hline & Being overweight & Being obese & Being overweight & Being obese \\
\hline Never breast fed $(n=858)$ & $11.4(9.3$ to 13.5$)$ & 4.3 (2.9 to 5.7$)$ & & \\
\hline Ever breast fed $(n=2873)$ & $10.8(9.7$ to 11.9$)$ & 3.8 (3.1 to 4.5$)$ & & \\
\hline \multicolumn{5}{|l|}{ Breast fed for: } \\
\hline$\leqslant 2$ months $(n=810)$ & 9.1 (7.1 to 11.1$)$ & 3.5 (2.2 to 4.8$)$ & 0.72 (0.54 to 0.95$)$ & 0.65 (0.41 to 1.00$)$ \\
\hline $3-4$ months $(n=504)$ & 9.7 (7.1 to 12.3$)$ & $3.4(1.8$ to 5.0$)$ & $0.86(0.61$ to 1.15$)$ & 0.83 (0.44 to 1.21$)$ \\
\hline 5-10 months $(n=1340)$ & 11.6 (9.9 to 13.3$)$ & $4.0(3.0$ to 5.1$)$ & $0.98(0.77$ to 1.24$)$ & 0.90 (0.58 to 1.22$)$ \\
\hline$>10$ months $(\mathrm{n}=219)$ & 14.6 (9.9 to 19.3$)$ & $4.6(1.8$ to 7.4$)$ & 1.29 (0.84 to 1.81$)$ & 1.05 (0.45 to 1.69$)$ \\
\hline \multicolumn{5}{|c|}{ Childhood social class (baseline, I and II)‡: } \\
\hline III & & & 0.75 (0.58 to 0.91$)$ & 1.10 (0.74 to 1.54$)$ \\
\hline IV and V & & & $1.13(0.87$ to 1.43$)$ & 1.47 (0.89 to 2.06$)$ \\
\hline \multicolumn{5}{|c|}{ Birth weight (baseline, $>2500 \mathrm{~g}$ ): } \\
\hline$<2500 \mathrm{~g}$ & & & $0.68(0.36$ to 1.26$)$ & $0.01(0.00$ to 106.52$)$ \\
\hline \multicolumn{5}{|c|}{ No of people per room at age 2 (baseline, $>1.5$ ) $\ddagger$ : } \\
\hline$<1.5$ & & & 1.32 (1.07 to 1.57$)$ & 1.79 (1.25 to 2.36$)$ \\
\hline \multicolumn{5}{|c|}{ Fat intake at age 4 in $\mathrm{g}$ (baseline, lowest three quarters): } \\
\hline Highest quarter & & & 1.23 (1.03 to 1.53$)$ & $1.22(0.87$ to 1.66$)$ \\
\hline
\end{tabular}

*Body mass index above 90th centile, using sex standardised reference group $(n=3891)$.

†Body mass index above 97 th centile. $¥ \mathrm{P}<0.05$.
1 Von Kries R, Koletzko B, Sauerwald T, von Mutius E, Barnert D, Grunert V, et al. Breast feeding and obesity: cross sectional study. BMJ 1999;319:147-50. (17 July.)

2 Wadsworth MEJ, Mann SL, Rodgers B, Kuh DL, Hilder WS, Yusuf EJ. Loss and representativeness in a 43 year follow-up of a national birth cohort J Epidemiol Community Health 1992:46:300-4.

3 Robinson MA.. A comparison of breastfeeding in 10 classes of the population. Arch Dis Child 1941;16:31-4.

4 Douglas JWB. The extent of breast-feeding in Great Britain in 1946, with special reference to the health and survival of children.J Obstet Gynaecol Br Empire 1950;57:336-61.

5 Whitehead R, Paul AA. Changes in infant feeding in Britain during this century. In: Infant nutrition and cardiovascular discase. Southapton: Medical Research Council Environent tal Epidemiology Unit, 1987. (Scientific report No 8.)

\section{Prolonging breast feeding to reduce obesity may be a burden}

EDITOR-Von Kries et al have shown that the prevalence of obesity in children aged 5 and 6 is dependent on the duration of breast feeding. ${ }^{1}$ A clear dose-response effect was observed even after adjustment for potential confounding factors. The authors concluded that in industrialised countries prolonged breast feeding may help reduce the prevalence of obesity in childhood. However, future studies should attempt to address the issue of why mothers do not start breast feeding or why they discontinue it, as these issues were not addressed by von Kries et al.

If a mother is overweight or obese this may interfere with both the initiation and duration of breast feeding. ${ }^{2}$ In a study of 514 women who were followed up for six months after the birth of their child, almost half of the women who started breast feeding felt at some stage that they did not have enough milk; $49 \%$ of those who subsequently sought advice from a health professional were advised to feed more often, and $42 \%$ said that they had been advised to bottle feed. ${ }^{3}$ An inadequate supply of breast milk was the most common reason given by mothers for discontinuing breast feeding.

In the light of findings that indicate that energy intake and nutritive sucking behaviour contribute significantly to measures of body weight and composition at 1 year of age, ${ }^{4}$ it seems likely that the mothers of heavier children are more likely to switch to bottle feeding earlier than mothers of less heavy children who have a lower energy intake. Thus, the recommendation that prolonging breast feeding might reduce the risk of obesity in childhood might put a considerable strain on both mother and child.

Johannes Hebebrand professor

Clinical Research Group, Department of Child and Adolescent Psychiatry, University of Marburg, Schützenstrasse 49, D-35033 Marburg, Germany

1 Von Kries R, Koletzko B, Sauerwald T, von Mutius E, Barnert D, Grunert V, et al. Breast feeding and obesity: cross sectional study. BMJ 1999;319:147-50. (17 July.)

2 Graffy JP. Mothers' attitudes to and experience of breast 2 Graffy JP. Mothers' attitudes to and experience of breast
feeding: a primary care study. Br J Gen Pract 1992;42:61-4. 3 Hilson JA, Rasmussen KM, Kjolhede CL. Maternal obesity and breast-feeding success in a rural population of white women. Am J Clin Nutr 1997;66:1371-8.

4 Stunkard AJ, Berkowitz RI, Stallings VA, Schoeller DA. Energy intake, not energy output, is a determinant of body size in infants. Am J Clin Nutr 1999;69:524-30. 


\section{Subspecialist psychiatrists are sometimes selective about whom they will treat}

EDITOR-The article by Kisely (on which one of us (AJP) wrote a commentary) ${ }^{1}$ and the responses to it show the difficulties that people with severe personality disorders present to health policymakers and the different views among mental health professionals who work with these patients. Haigh's letter ${ }^{2}$ and the longer electronic version of $\mathrm{it}^{3}$ provide an insight into how a psychiatrist working in a narrow subspecialty can lose sight of the realities of psychiatric practice. Haigh has taken offence at the description in the commentary of a patient who deliberately harmed herself (her behaviour led to over 100 operations) and who caused distress and dismay among social workers, the police, the legal profession, and all health workers who tried to help her. The vignette had to be brief to preserve anonymity, but it was entirely factual.

Haigh accuses one of us (and, by implication, the multidisciplinary team) of being unprofessional and is critical of our inability to form a therapeutic relationship with this patient. In the three years before the patient came into our ward numerous mental health professionals considered her to be psychiatrically untreatable. Because her life was in danger, our multidisciplinary team on a general psychiatric ward opted to attempt to treat her under the terms of the Mental Health (Scotland) Act. We were able to carry out a comprehensive assessment and reduce her self harm and exposure to general anaesthetics. We could not, however, successfully change her behaviour despite our best efforts over 14 months. Her local health board said that it would underwrite any extracontractual referral, but none of the specialist units for the treatment of personality disorder would accept her. After discharge she embarked on an orgy of self mutilation until a general psychiatric unit in London began a programme of treatment under the Mental Health Act.

Haigh seems proud of his therapeutic community for day patients with personality disorders, where "selection and drop out is often part of the clinical process." We suspect that he can effectively limit his distress and dismay in dealing with patients because he can decline difficult referrals to his specialist unit. Is it not, in fact, unprofessional for Haigh to deny the emotional burden on colleagues who are prepared to try to help deeply disturbed patients?

This exchange between Haigh and ourselves will, we hope, give general readers some understanding of this topsy turvy part of British psychiatry. Those who claim to have the greatest skills in dealing with personality disorders do not accept severely affected patients. This leaves general psychiatric teams to do their best to help these patients, often in the most difficult circumstances. Policymakers who are desperate for a solution to the inadequacies of services for severe personality disorders should bear these issues in mind when subspecialist psychiatrists from centres of excellence ask for additional funding.

Anthony J Pelosi consultant psychiatrist Irene McKee clinical nurse specialist Department of Psychiatry, Hairmyres Hospital, East Kilbride G75 8RG

1 Kisely S. Psychotherapy for severe personality disorder: exploring the limits of evidence based purchasing. [With commentary by A J Pelosi.] BMJ 1999;318:1410-2 (22 May.)

2 Haigh R. Psychotherapy for severe personality disorder BMJ 1999;319:709. (11 September.)

Haigh R. Therapeutic communities. eBMJ 1999;318. (www. bmj.com/cgi/eletters/318/7195/1410.)

\section{Effectiveness of glucocorticoids in treating croup}

\section{Authors acknowledge Cochrane Collaboration}

EDITOR-It has been brought to my attention that we omitted some key acknowledgments in our recently published systematic review of glucocorticoids for the treatment of croup. The protocol for our review was registered with the Acute Respiratory Infection Review Group of the Cochrane Collaboration in 1997. Our review is currently under revision with the review group and will be published in the Cochrane Database of Systematic Reviews. The Acute Respiratory Infection Review Group was very helpful in searching its database of trials identified through handsearching of relevant journals and in providing insightful comments on our protocol.

One advantage of having our study published in the Cochrane Database of Systematic Reviews is that we will be able to update the review as new evidence is identified. The $B M$ /s policy of permitting duplicate publication with the Cochrane Collaboration is extremely important. I hope that other journals join in this support of the Cochrane Collaboration through like minded policies.

\section{Terry P Klassen chair}

Department of Paediatrics, University of Alberta, 2C3.67 Walter C Mackenzie Health Sciences Centre, Edmonton, Alberta, Canada T6G 2R7 terry.klassen@ualberta.ca

\section{Ausejo M, Saenz A, Pham Ba', Kellner JD, Johnson DW, Moher D, et al. The effectiveness of glucocorticoids in treating croup: meta-analysis. BMJ 1999;319:595-600. (4 September.)}

\section{General practitioners must be ready to treat children}

EDITOR-The meta-analysis by Ausejo et al is timely as the croup season approaches. Despite the usefulness of corticosteroids having been recognised for many years, our experience is that children rarely receive them in any form before admission to hospital.

Geelhoed et al showed the benefit of a small single dose of dexamethasone for outpatient croup in 1996, ${ }^{2}$ and Godden et al confirmed the usefulness of nebulised budesonide. ${ }^{3}$ Despite this, doctors still seem to be reluctant to treat mild croup, which usually lasts three to four days if left untreated.
Our review of the case notes of children admitted with croup between November 1996 and October 1997 identified 51 cases in a total paediatric population of 65000 . General practice referrals accounted for three fifths of admissions (31/51); none of the children admitted as general practice referrals had received either inhaled or systemic steroid apart from one child seen at a primary care casualty department, who received hydrocortisone.

Although formal croup scores were not recorded on admission, most cases were mild and 46 of the children were discharged within 16 hours of admission-that is, the next morning if admitted at night or the same day if admitted in the early hours of the day. The cough lasted for over eight hours in 28 cases, which suggests that there is an opportunity for treatment if parents are encouraged to seek help. As discussed by Thomson in her commentary ${ }^{3}$ in referring to the paper of Geelhoed et al, ${ }^{2}$ dexamethasone is as cheap as, easier to administer than, and as effective as nebulised corticosteroids. It should perhaps be added to the list of "black bag essentials"-albeit that the main determinant of treatment or indeed admission to hospital may be the degree of parental anxiety generated by caring for a child with stridor in the middle of the night.

Angela J Tillett specialist registrar in paediatrics Department of Paediatrics, Addenbrooke's NHS Trust, Cambridge CB2 2QQ lawr@globalnet.co.uk

James D M Gould consultant paediatrician Department of Child Health, Ipswich Hospital NHS Trust, Ipswich IP4 5PD

1 Ausejo M, Saenz A, Pham Ba', Kellner JD, Johnson DW, Moher D, et al. The effectiveness of glucocorticoids in treating croup: meta-analysis. BMJ 1999;319:595-600. (4 September

2 Geelhoed G, Turner J, Macdonald W. Efficacy of a small single dose of oral dexamethasone for outpatient croup: double blind placebo controlled trial. BMJ 1996:313:140-2. 3 Godden C, Campbell M, Hussey M, Cogswell J. Double bodden C, Campbell M, Hussey M, Cogswell J. Double blind placebo controlled trial of nebulised budesonide for Child 1997;76:155-8.

Suitable formulations of oral glucocorticoids are available in primary care

EDitor-The meta-analysis of Ausejo et al shows that glucocorticoids improve the course of croup in children who are seen in emergency departments or admitted to hospital. ${ }^{1}$ Many children with croup are not referred to hospital, so how are doctors in primary care to respond?

I see no reason to suppose that children with croup should not benefit from steroids just because they are in the community, but unfortunately dexamethasone is available only as tablets in the community in the United Kingdom. This is not a suitable formulation for small children.

Nebulised budesonide is available but is expensive and inconvenient and reaches its expiry date alarmingly fast. As a result in our practice we use soluble betamethasone tablets, which are equipotent to dexamethasone and can be dissolved in a drink. I have also observed that they have the advantage 
of tasting more palatable than soluble prednisolone tablets.

The paper that prompted our change in practice was published in the $B M J$ in $1996 .{ }^{2}$ For the past two years we have used a single oral dose of $0.15 \mathrm{mg} / \mathrm{kg}$ (prescribed as $500 \mu \mathrm{g}$ soluble betamethasone tablets to dissolve in a drink) to treat children in the community with croup.

Others who wish to use oral steroids for children with croup in the community may find this information on available formulations useful while we all wait for a much needed randomised controlled trial of glucocorticoids in croup in primary care.

Christopher Cates general practitioner

Manor View Practice, Bushey Health Centre,

London Road, Bushey, Hertfordshire WD2 2NN

chriscates@email.msn.com

1 Ausejo M, Saenz A, Pham Ba', Kellner JD, Johnson DW, Moher D, et al. The effectiveness of glucocorticoids in treating croup: meta-analysis. BMJ 1999;319:595-600. (4 September.)

2 Geelhoed G, Turner J, Macdonald W. Efficacy of a small single dose of oral dexamethasone for outpatient croup: a single dose of oral dexamethasone for outpatient croup: a
double blind placebo controlled clinical trial. BMJ double blind pa6:313:140-2.

Children with croup should receive corticosteroids in primary care: results of audit

EDITOR-Corticosteroids can reduce the symptoms and duration of stay in hospital for children with croup (acute laryngotracheobronchitis). ${ }^{1}$ We would like to bring the results of our audit on the management of children with croup to the attention of colleagues working in primary care.

We studied 101 case records of children with croup assessed in Leicester Royal Infirmary (July to December 1998). Of 58 children referred by their general practitioners, 18 had received antibiotics, six salbuta$\mathrm{mol}$, and two steam inhalation. Steroids were not given to any of the children. Of the 101 children, 78 were admitted, and, of these, 56 stayed less than 24 hours. The need for inpatient care might have been avoided in this group if corticosteroids had been given earlier in the illness.

It is disappointing that none of the children received steroids before their arrival at the hospital. There is clear evidence that oral dexamethasone or nebulised budesonide results in clinical improvement in outpatients with mild to moderate croup, reducing the need for admission. ${ }^{23}$ One oral dose of dexamethasone $(0.15 \mathrm{mg} / \mathrm{kg})$ is effective in reducing the need for further medical care in mild croup. ${ }^{4}$ Prednisolone has not been widely studied, but equivalent doses $(1 \mathrm{mg} / \mathrm{kg})$ would be useful. ${ }^{5}$

Well designed trials have found a dramatic reduction in symptoms of airway obstruction as early as one hour after treatment. Substantial gains are achieved by treating all children with croup with steroids: fewer transfers to intensive care, shorter hospital stays, and cost savings.

We recommend that all children with croup should be given one oral dose of dexamethasone or prednisolone as soon as the diagnosis is made. When the diagnosis is in doubt or the clinical condition warrants admission to hospital, children should be referred in the usual way.

S Jothimurugan senior house officer

Jothidevi@hotmail.com

Zoaka Hassan honorary clinical fellow

M Silverman professor of child health

University Department of Child Health, Leicester

Royal Infirmary, PO Box 65, Leicester LE2 7LX

1 Ausejo M, Saenz A, Pham Ba', Kellner JD, Johnson DW, Moher D, et al. The effectiveness of glucocorticoids in treating croup: meta-analysis. BMJ 1999;319:595-600. (4 September.)

Klassen TP, Feldman ME, Watters LK, Sutcliffe T, Rowe PC Nebulised budesonide for children with mild to moderate croup. N Engl J Med 1994.331:285-9.

coup. N Engl J Med 1994;31:285-9. Cruz MN, Stewart G, Rosenberg N. Use of dexamethason in the outpatient management of acute laryngo tracheitis.

4 Geelhoed GC, Turner J, Macdonald WB. Efficacy of a small single dose of oral dexamethasone for outpatient croup: a double blind placebo controlled clinical trial. $B M$ 1996;313:140-2.

5 Macdonald WBG, Geelhoed GC. Management of child-

hood croup. Thorax 1997;52:757-9

\section{Overreaction to the Paddington rail disaster may not be beneficial in the long run}

EDITOR-Years ago I remember Lord Rothschild in his Reith lecture describing how public opinion cannot put disasters into their proper context, resulting in distortion of expenditure on accident prevention. The Paddington rail disaster was tragic, but public response was the overreaction he might have predicted, particularly in view of the fire and initial overestimation of casualties. The editorial by Cocks does nothing to redress the

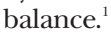

The uninitiated reader could not guess that current systems require more than the mere missing of a red light to pass a signal at danger, that trials have shown difficulties in applying available sophisticated systems, and that nearly all continental high speed trains run on specially built tracks. Land shortage and strict planning laws-exploited by the same political forces that demand absolute safety-have prevented their construction in this country, for example, in Kent. Rail travel is comparatively safe, the annual toll being two orders less than that on the road. A presumed conflict between safety and profit is emotionally satisfying but a red herring. The conflict applies equally to the private and public sectors, private industry requiring efficiency to satisfy investors' ambition and the public sector to satisfy Treasury parsimony.

The real conflict is between safety and the other interests of passengers: punctuality, speed, and economy. Both sides of the equation have implications for life and limb. Absolute safety is impossible. Even if this were achieved on rail, so small is the toll relative to that on the road that if it were made at the expense of passengers' other legitimate interests, so shifting them back to the road, loss of life directly through traffic accidents and indirectly through pollution would be far greater. This danger can only be enhanced by the current misconception that railways are dangerous, and getting more dangerous since privatisation (the timescale required is too short to resolve this).

The responsible attitude is to accept that Paddington was a tragedy, but overreaction, rather than producing long term benefits, might make those running the railways so fearful of accidents and subject to such severe controls that they are no longer able to do their job well enough to compete with far more dangerous and polluting modes of transport. In particular, comparatively simple measures such as the provision of more catch points (which would have prevented the collision) and graded crossings might be far cheaper, more cost effective, and less disruptive than the introduction of inflexible control systems that cannot be overridden.

C K Connolly consultant physician

South Durham Health Care Trust, Darlington Memorial Hospital, Darlington DL3 6HX

1 Cocks RA. Accidents that should never have happened. BMJ 1999;319:1018-9. (16 October.)

\section{Doctors are still committing genocide}

EDIToR-The otherwise excellent special issue on medicine and international law (14 August) did not describe, deplore, or explain that doctors have committed genocide, are still doing so, and may well do so in the future.

Leading doctors were among the decision makers responsible for a million or more Armenians dying in Turkey in 1915. Between 1976 and 1983, Argentine doctors took away, for adoption by military or police officers, hundreds of babies born to detained political dissidents who later "disappeared," usually from aircraft into the Atlantic. Serbian doctors have been indicted by the International Criminal Tribunal at The Hague for their part in massacres in Bosnia and Croatia. Hutu doctors led killings of Tutsis in Rwanda. Doctors admitting to these crimes blamed "loss of control ... collective madness" or that "traitors had found a niche for themselves in the bosom of the fatherland; they were dangerous microbes. Isn't it the duty of a doctor to destroy these microbes?"1

There are consistent psychological and sociological experiments suggesting that people at all levels of society will be ready to do what they told or to obey explicit orders to kill. Doctors are clearly no exception, and one can only hope that the humanisation programmes recommended in papers in this special issue will make genocide rarer in the future.

J H Baron honorary professorial lecturer, Mount Sinai School of Medicine, New York, NY 10019, USA 21c Randolph Crescent, London W9 1DP

1 Baron JH. Genocidal doctors. JR Soc Med 1999;92:590-3.

Rapid responses
$\begin{aligned} & \text { Correspondence submitted electronically } \\ & \text { is available on our website www.bmj.com }\end{aligned}$

